\title{
Prevalence of anemia in pregnancy and its outcome in rural Tertiary Care Centre in India
}

\author{
Sowmya Gopinath ${ }^{1, *}$, Dhananjaya B. S. ${ }^{2}$, Kakarla Sreelasya ${ }^{3}$, Chandana Krishna ${ }^{4}$ \\ ${ }^{1}$ Assistant Professor, ${ }^{2}$ Professor \& HOD, ${ }^{3}$ Junior Resident, Dept. of Obstetrics and Gynecology, ${ }^{4}$ Assistant Professor, Dept. of \\ Community Medicine, Sree Siddhartha Medical College, Tumkur, Karnataka, India
}

*Corresponding Author:

Email: sowmyasubri@gmail.com

\begin{abstract}
Anemia in pregnancy is a major health problem in developing countries. Haemorrhage ranks first in the list of maternal mortality in developing countries.

Materials and Methods: A prospective study on all anaemic pregnant patients (according to WHO) admitted to labour room of more than 28 weeks gestational age from May 2015 to May 2017 in Sri Siddhartha Medical College, Tumkur were included in the study and appropriately treated.

Demographic factors like age, education, socioeconomic status, parity, birth spacing and intake of iron supplements was studied. Maternal and perinatal outcome was also studied.

Results: Among 2982 deliveries, 32 cases were excluded according to exclusion criteria. About 1903 were found to be anemic. In these cases, $61 \%$ were in $20-24$ yrs age group, $35 \%$ patients educated upto middle school, $71 \%$ belonged to low socioeconomic status, $62.1 \%$ had less than 2 years of birth spacing. All these factors were statistically significant. But $38 \%$ cases had not received iron supplements.

Although mild anemia cases were uneventful, moderate and severe anaemia cases had maternal complications. In moderate anemia, 4\% patients had PPH and received blood and blood products, $10 \%$ had puerperial fever and rest uneventful. Severe anemia had significant outcome: preterm labour (38\%), preeclampsia (20\%), IUGR (10\%), intrauterine fetal demise (8\%), abruption placenta $(7 \%)$,

placenta previa (1\%), puerperal fever $(7.2 \%)$, cardiac failure $(0.8 \%)$, PPH (8\%). Maternal mortality was noted in 3 patients. About 35 neonates of mild anaemic cases, 65 neonates of moderate anaemic cases and nearly $46.5 \%$ of severe anaemia cases had complications.

Conclusion: Prevalence of anemia is most common in rural population. Demographic factors also play a very important role. Effective management of anemia cases definitely prevents maternal and perinatal mortality.
\end{abstract}

Keywords: Severe anaemia, Demographic factors, Maternal mortality, Perinatal mortality.

\section{Introduction}

Anemia in pregnancy is a major problem in developing countries. ${ }^{1}$ The incidence of anemia in pregnancy ranges widely from $40 \%$ to $80 \%$ in the tropics compared to $10 \%$ to $20 \%$ in the developed countries.

Of 1000 Indian women, half were anemic at some point, and $40 \%$ were throughout pregnancy. ${ }^{2}$ Prevalence of anaemia in South Asian countries ranks first in the world. This contributes to half of global maternal deaths.

Anemia is responsible for $20 \%$ of maternal deaths in the developing countries. Despite the various National Programmes, the magnitude of anaemia as a public health problem still remains high.

The causes of anaemia in pregnancy and their frequency are dependent on multiple factors such as geography, ethnicity, nutritional status, preexisting iron status and prenatal iron supplementation. ${ }^{2}$ Other factors like parity, socioeconomic status, birth spacing also play a very important role.

There are many studies available on the effect of anaemia on pregnancy outcome. Kumar and colleagues (2013 studied 1000 Indian women and concluded that second and third trimester anaemia was associated with preterm labour and low birth weight. ${ }^{3}$ Chang and associates studied 850 children born to iron deficiency anaemic mothers. Children without iron supplementation had lower mental development at 12 , 18 and 24 months of age, suggesting that prenatal iron deficiency is associated with mental development. ${ }^{4}$

The aim of the study was to find the prevalence of anaemia in rural pregnant patients, role of demographic factors, maternal and perinatal outcome.

\section{Material and Methods}

Study was conducted in Sri Siddhartha Medical College which is situated in rural area of Tumkur district. After obtaining clearance from instituitional ethical committee, a prospective study was conducted and 2985 patients were enrolled in the study.

The data was collected from the study subjects after taking the informed consent using a pretested proforma.

\section{Study subjects}

Inclusion Criteria: Pregnant patients more than 28 weeks with anaemia admitted to labour room in Sri Siddhartha Medical College, Tumkur were included in the study and appropriately treated.

\section{Exclusion Criteria:}

Anaemia due to acute blood loss. 
Multiple pregnancy.

Chronic diseases like tuberculosis, renal disease, heart disease, thyroid disorders.

Haemolytic anaemia.

Diagnosis of anaemia was made depending on $\mathrm{Hb} \%$, hematocrit, Blood indicies and peripheral blood smear.

\section{Severity of Anemia was graded as per WHO:}

$\mathrm{Hb} \%-11$ gm $\%$ : 723 (Mild)

$\mathrm{Hb} \%-7-9 \mathrm{gm} \%$ : 647(Moderate)

$\mathrm{Hb} \%-<7 \mathrm{gm} \%$ : 533(Severe)

Patients were accordingly treated and delivered.

Study period: May 2015 to April 2017. Demographic factors like age, education, socioeconomic status, parity, birth spacing and intake of iron supplements was studied.

Maternal and perinatal outcomes were studied.

Data was tabulated in MS Excel 2000 and was analysed using SPSS software version 18.0. Descriptive statistics was used and association was analysed using Chi-Square test.

\section{Results}

Out of 2985 deliveries during the study period, 32 were excluded as per exclusion criteria and 1903 were found to have anaemia. The prevalence of anaemia is $64.5 \%$. There were 723 mild anaemia cases, 647 moderate anaemia and 533 severe anaemia.

Table 1: Age distribution

\begin{tabular}{|l|c|c|c|c|c|c|c|}
\hline \multicolumn{1}{|c|}{$\begin{array}{c}\text { Age } \\
\text { Years) }\end{array}$} & \multicolumn{2}{c|}{$\begin{array}{c}\text { Mild } \\
\text { n(\%) }\end{array}$} & \multicolumn{2}{c|}{$\begin{array}{c}\text { Moderate } \\
\text { n(\%) }\end{array}$} & \multicolumn{2}{c|}{$\begin{array}{c}\text { Severe } \\
\text { n(\%) }\end{array}$} & Total \\
\hline$<20$ & 75 & $(10.4 \%)$ & 97 & $(15 \%)$ & 94 & $(17.6 \%)$ & 266 \\
\hline $20-24$ & $331(45.8 \%)$ & \multicolumn{2}{|c|}{$476(73.6 \%)$} & $353(66.2 \%)$ & 1160 \\
\hline $25-29$ & $294(40.6 \%)$ & 60 & $(9.3 \%)$ & 65 & $(12.2 \%)$ & 419 \\
\hline$>30$ & 23 & $(3.2 \%)$ & 14 & $(2.1 \%)$ & 21 & $(4 \%)$ & 88 \\
\hline Total & \multicolumn{2}{|c|}{723} & \multicolumn{2}{|c|}{647} & \multicolumn{2}{|c|}{533} & 1903 \\
\hline $\begin{array}{l}\text { Chi square=247.27 } \\
\& \text { p }<0.05\end{array}$ & \multicolumn{3}{|l|}{} \\
\hline
\end{tabular}

Table 2: Distribution of education, socio economic status, parity, birth spacing and iron supplementation

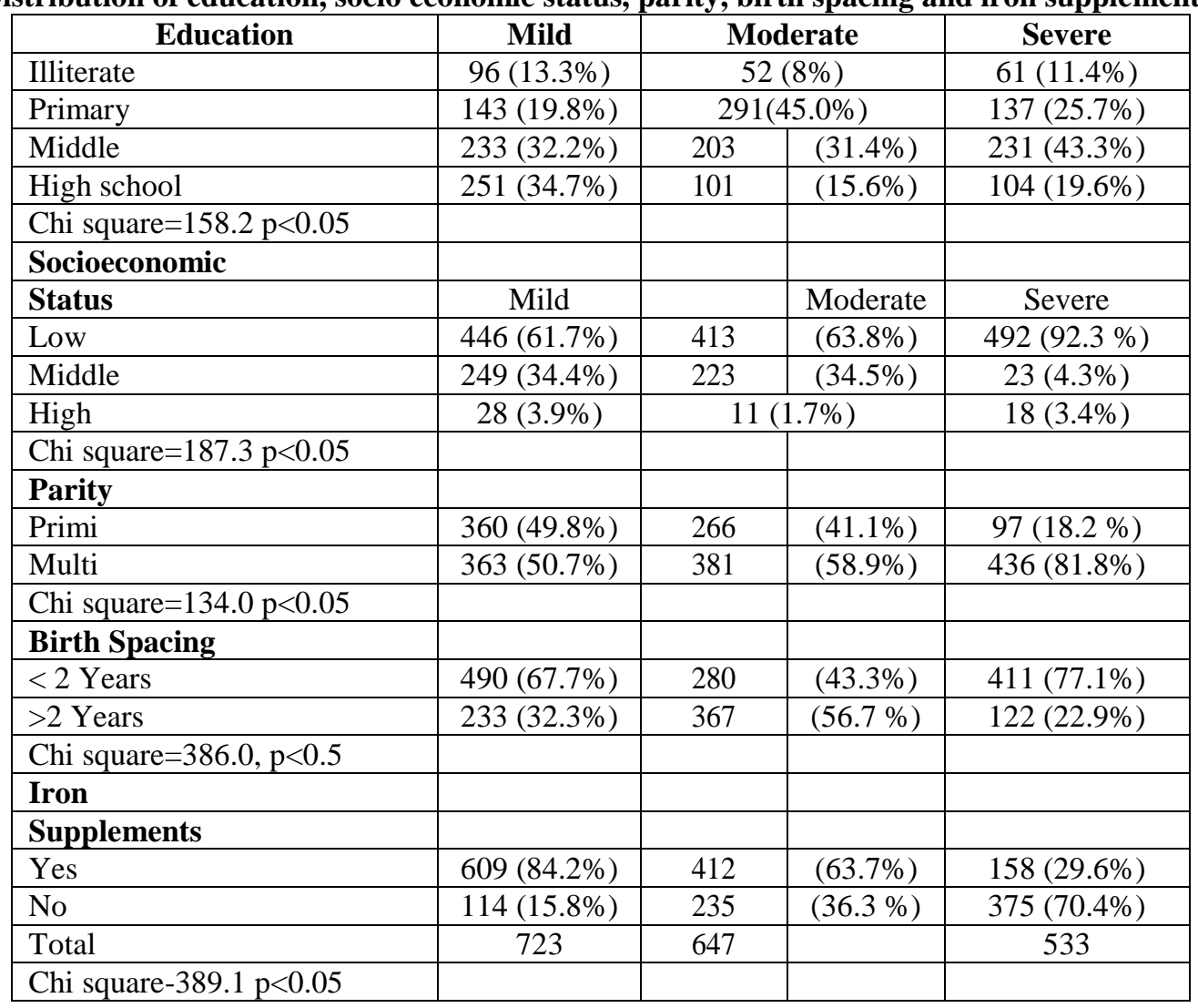

Out of 1903 cases, only $9.7 \%$ of cases were unbooked. Severe anaemia was significantly more prevalent in 
unbooked cases.

Table 3: Mode of delivery

\begin{tabular}{|l|c|c|c|c|c|}
\hline VBAC & 65 & $(9 \%)$ & $7(1.1 \%)$ & \multicolumn{2}{|c|}{$23(4.3 \%)$} \\
\hline Vaginal & \multicolumn{2}{|c|}{$476(65.8 \%)$} & $471(72.8 \%)$ & 347 & $(65 \%)$ \\
\hline & \multicolumn{2}{|c|}{} & & & \\
\hline Instrumental & 20 & $(2.8 \%)$ & $17(2.6 \%)$ & $20(3.8 \%)$ \\
\hline & \multicolumn{2}{|c|}{$162(22.4 \%)$} & $152(23.5 \%)$ & 143 & $(26.8 \%)$ \\
\hline LSCS & \multicolumn{2}{|c|}{723} & 647 & & 533 \\
\hline $\begin{array}{l}\text { Total } \\
\text { Chi square=50.8,p<0.05 }\end{array}$ & \multicolumn{2}{|c|}{723} & & & \\
\hline
\end{tabular}

\section{Maternal Outcome}

Though mild anemic cases were uneventful, moderate anemic patients had adverse outcome. Twenty six patients had PPH and were transfused blood and blood products. Sixty seven patients had purpueral fever and rest were uneventful.

Table 4: Maternal outcome in severe anemia

\begin{tabular}{|l|c|c|}
\hline \multicolumn{1}{|c|}{ Severe Anemia Outcome } & n & \% \\
\hline Uneventful & 27 & 5.1 \\
\hline Preterm labour & 202 & 37.9 \\
\hline PPH & 43 & 8.1 \\
\hline IUGR & 52 & 9.8 \\
\hline IUFD & 21 & 3.9 \\
\hline Abruptio placenta & 35 & 6.5 \\
\hline Placenta previa & 03 & 0.6 \\
\hline Puerperal fever & 39 & 7.3 \\
\hline Cardiac failure & 04 & 0.7 \\
\hline Maternal mortality & 03 & 0.6 \\
\hline Preeclampsia & 104 & 19.5 \\
\hline
\end{tabular}

Out of 533 severe anaemic patients, only 27 of them had an uneventful outcome. About $94.9 \%$ patients had complications. Preterm labour was a major complication contributing to around $39.5 \%$. Preeclampsia was found in 102 cases. In these 102 patients, 39 patients had an additional complication IUGR. Therefore, only 13 patients with severe anaemia had IUGR accounting to $2.4 \%$.

Table 5: Perinatal Outcome

\begin{tabular}{|c|c|c|c|c|c|c|}
\hline Perinatal & \multicolumn{2}{|c|}{ Mild } & \multicolumn{2}{|c|}{ Moderate } & \multicolumn{2}{|c|}{ Severe } \\
\hline IUD & \multicolumn{2}{|c|}{$8(1.1 \%)$} & 12 & $(1.85 \%)$ & 21 & $(3.9 \%)$ \\
\hline FSB & \multicolumn{2}{|c|}{$2(0.28 \%)$} & \multicolumn{2}{|c|}{$4(0.63 \%)$} & 02 & $(0.38 \%)$ \\
\hline $\begin{array}{l}\text { NICU } \\
\text { Admissions }\end{array}$ & 12 & $(1.66 \%)$ & 28 & $(4.46 \%)$ & 43 & $(8.07 \%)$ \\
\hline NND & 02 & $(0.28 \%)$ & 03 & $(0.48 \%)$ & 09 & $(1.69 \%)$ \\
\hline LBW & 11 & $(1.52 \%)$ & 18 & $(2.88 \%)$ & 73 & $(13.7 \%)$ \\
\hline Total & 35 & $(4.84 \%)$ & 65 & $(10.37 \%)$ & \multicolumn{2}{|c|}{$248(46.5 \%)$} \\
\hline
\end{tabular}

chi square $=14.4, \mathrm{p}=0.07$

Out of 723 mild anaemic cases, 35 (4.84\%) had perinatal complications. The perinatal complications were more in severe anaemia cases accounting to $46.5 \%$.

\section{Discussion}

In the present study, the prevalence, demographic factors, maternal outcome and the perinatal outcome were analysed.

The prevalence of anaemia was $64.5 \%$. The prevalence in similar type of studies ${ }^{5,6}$ were $42.6 \%$ and $74.84 \%$ 
respectively. Our results are close to the study done in Nepal by Bondevik ${ }^{7}$ who quoted the prevalence of $62.2 \%$. Though in India, we follow ICMR criteria for grading anaemia, WHO GRADING of anaemia was followed in present study so as to compare with other international study. The causes of the high prevalence is probably high because of open air defecation, food taboo, faulty diet.

Anemia was more prevalent in age group of 20-24 years. This is in contrast to the study by Ahmad et al, ${ }^{8}$ which involved the pregnant patients in rural medical college, Ahmedabad, the prevalence was more in the age group $<20$ years. In the study by Gautham et al, ${ }^{6}$ which was a study conducted in a rural area in Delhi, 114 pregnant women were studied, prevalence of severe anaemia was significantly higher in age group $>25$ years. The reason for the highest incidence of anaemia in the age group of 20-24 years in our study is that the pregnancies and child birth is more common in this age group. Pregnant women belonging to low socioeconomic status had higher prevalence which is similar to study by Ahmad, ${ }^{8}$ S. Bisui. ${ }^{9}$

Multigravida, birthspacing of $<2$ years had higher preponderance for anemia which is similar to studies N.R.Vanden Broc et al, ${ }^{10}$ Raghuram et a ${ }^{11}$ respectively. This is because the replenishment of iron stores take about 2 years and lack of spacing contraception despite effective couselling.

Table 6: Anemia and mode of delivery

\begin{tabular}{|l|c|c|c|c|c|c|}
\hline & \multicolumn{2}{|c|}{ M Nair etal $^{\mathbf{1 2}}$} & & \multicolumn{2}{c|}{ Present study } & \\
\hline Mode of & Mild & Moderate & Severe & Mild & Moderate & Severe \\
\hline Delivery & Anemia & anemia & Anemia & anemia & anemia & Anemia \\
\hline Vaginal & $44.1 \%$ & $61.2 \%$ & $66.7 \%$ & $74.6 \%$ & $73.0 \%$ & $69.4 \%$ \\
\hline Instrumental & $2.7 \%$ & $1.2 \%$ & $4.7 \%$ & $2.8 \%$ & $2.6 \%$ & $3.3 \%$ \\
\hline $\begin{array}{l}\text { Caesarean } \\
\text { Section }\end{array}$ & $52.6 \%$ & $37.0 \%$ & $28.6 \%$ & $22.4 \%$ & $22.5 \%$ & $26 \%$ \\
\hline
\end{tabular}

Table 7: Maternal Outcome in Severe Anemia

\begin{tabular}{|l|c|c|c|}
\hline \multicolumn{1}{|c|}{ Complications } & Rohila etal $^{\mathbf{1 3}}$ & Nirmala etal $^{\mathbf{1 4}}$ & Present study $^{-17.3 \%}$ \\
\hline Preeclampsia & $17.7 \%$ & $25.33 \%$ & $19.5 \%$ \\
\hline Preterm labour & $18.7 \%$ & $44.68 \%$ & $37.9 \%$ \\
\hline Abruptio placenta & $3.12 \%$ & $8.5 \%$ & $6.5 \%$ \\
\hline Placenta previa & - & $2 \%$ & $0.6 \%$ \\
\hline IUFD & - & - & $3.9 \%$ \\
\hline IUGR & $33.3 \%$ & $12.77 \%$ & $9.8 \%$ \\
\hline PPH & $25.5 \%$ & $6.4 \%$ & $8.1 \%$ \\
\hline Cardiac failure & $9.37 \%$ & $1.06 \%$ & $0.7 \%$ \\
\hline Maternal mortality & $6.25 \%$ & $1.06 \%$ & $0.6 \%$ \\
\hline
\end{tabular}

Perinatal outcome and anaemia

In the present study, NICU admission occurred in $14.2 \%$ neonates. About $18.1 \%$ of neonates weighed less than $2.5 \mathrm{Kg}$. Our results are almost similar to the study by Anjanappa etal(15) in which NICU admission occurred in $13.1 \%$ and LBW in neonates complicated in $21 \%$ cases.In the study by FW Lone etal (16), the risk of LBW in the anaemic population was 1.9 times higher. The risk associated of IUD was 3.7 times higher in anaemic women.

\section{Conclusion}

Anaemia is more prevalent in rural pregnant women. Demographic factors play a significant role. Anaemia in pregnancy has a significant association with younger age groups, lower socioeconomic status, high parity, birth spacing $<2$ years and poor antenatal care. Education level has no much significant impact as per the present study. As severe anaemia was associated with significant maternal complications, following steps will be useful.
Education regarding the intake of iron supplements, nutritious diet, hygienic practices and birth spacing. Increase number of antenatal follow ups would help in prevention of anemia and its complications in women at a higher risk.

Effective management of anaemia cases reduces both maternal morbidity and mortality.

\section{References}

1. Singh P, Khan S, Mittal RK. Anemia during Pregnancy in the Women of Western Nepal. Bali Medical Journal (BMJ). 2013. 2(1):14-6.

2. Cunningham FG, editors. Williams obstetrics- 24th ed. USA. Mc Graw-Hill. 2014:832.

3. Kumar KJ, Asha N, Murthy DS, Sujatha M. Maternal anaemia in various trimesters and its effect on newborn weight and maturity: an observational study. Int J Prev Med. 2013 Feb;4(2):193-9.

4. Chang $\mathrm{S}^{1}$, Zeng L, Brouwer ID, Kok FJ, Yan H.Effect of iron deficiency anemia in pregnancy on child mental development in rural China. Paeds 2013 Mar;131(3):e755-63. 
5. Marhatta R. Study of anemia in pregnancy and its outcome in Nepal Medical college Teaching Hospital, Kathmandu, Nepal. Nepal Med coll J 2007;9:270-4.

6. Gautam VP, Bansal Y, Taneja DK, Saha R. Prevalence of Anaemia Amongst Pregnant Women And Its SocioDemographic Associates in a Rural Area of Delhi Indian J Community Med. 2002 Oct.-Dec;27(4):157-60.

7. Bondevik GT ${ }^{1}$, Eskeland B, Ulvik RJ, Ulstein M, Lie RT, Schneede J, Kvåle G Anaemia in pregnancy: possible causes and risk factors in Nepali women Eur J Clin Nutr. $2000 \mathrm{Jan} ; 54(1): 3-8$.

8. Ahmad N, Kalakoti P, Bano R, Syed MMA. The prevalence of anaemia and associated factors in pregnant women in a rural Indian community. AMJ 2010, 3, 5, 276-280.

9. Bisoi S, Haldar D, Majumdar TK, Bhattacharya N, Sarkar GN, Ray SK. Correlates of Anemia Among Pregnant Women in a Rural Area of West Bengal. The Journal of Family Welfare. 2013 Jun;57(1):72-8.

10. . Van den Broek NR, Letsky EA. Anaemia in pregnancy in southern Malawi: prevalence and risk factors. British Journal of Obstetrics and Gynaecology. 2000 Apr; 107:445-51.

11. Raghuram V, Anil M, Jayaram S. Prevalence of anaemia amongst women in the reproductive age group in a rural area in south India. Int J Biol Med Res. 2012;3(2):1482-4.

12. Nair M, Choudhury MK, Choudhury SS, Kakoty SD, Sarma UC, Webster P etal. Association between maternal anaemia and pregnancy outcomes: a cohort study in Assam, India. BMJ Global Health. 2016 Apr; 1(1).

13. Rohilla M, Ravindra A, Dhaliwal LK, Chopra S. Severe anaemia in pregnancy: A territory hospital from Northen India. J ObsetGynaecology 2010:30(7):694-6.

14. NirmalaDevi B, Varalaxmi B, Jyothirmayi T, Lahari N. Maternal outcome in pregnancy with severe anaemia: Prospective study in a tertiary care hospital in Andhra Pradesh. IOSR Journal of Dental and Medical Sciences (IOSR-JDMS). 2015 Apr;14(4):6-10.

15. Anjanappa B, Radhika BH, Nataraja HG, Ramaiah R, Sathya. Maternal haemoglobin and perinatal outcome. Int J Reprod Contracept Obstet Gynecol. 2015 Oct; $4(5): 1335-8$.

16. Lone FW, Qureshi RN, Emanuel F. Maternal anaemia and its impact on perinatal outcome. Tropical Medicine and International Health. 2004 Apr;9(4):486-90. 